\title{
Management of business process reengineering projects: a case study
}

\author{
Chandrashekhar S. Joshi ${ }^{1}$ \& P.G. Dangwal ${ }^{2}$ \\ 1 CompuBee Technologies, Maharashtra, India \\ 2 Department of Shri Guru Ram Rai Institute of Technology and Science, Uttarakhand, India
}

\begin{abstract}
Business process reengineering (BPR) projects are undertaken by outward-looking companies that are looking for significant change in their performance and wanting radical changes in the chosen parameters. Generally, these companies are trendsetters in their respective industries. BPR projects take longer time for completion and may require significant capital inflows as well. This paper discusses BPR, special requirements/considerations for BPR project management and, through a case analysis, seeks to identify and emphasise the critical success factors for the implementation of a BPR project.
\end{abstract}

\section{Introduction}

Business process reengineering (BPR) is defined as the fundamental rethinking and redesign of business processes to achieve dramatic improvements in critical, contemporary measures of performance, such as cost, quality, service and speed (Hammer \& Champy 1993). This means that BPR requires radical transformation as opposed to incremental change and hence the fundamental question an organisation must address before adopting BPR is whether there is a compelling business case for change. The basic premise of BPR is that the rapid redesign of critical core processes of a company will generate breakthrough improvements in the company's performance and generate competitive advantage in the global marketplace.

As the BPR project covers the operations of the entire organisation across the globe and involves everybody, i.e. from top management to the grassroots-level employees, its project management has to be different and has to be carried out in such a way that the project objectives are achieved within the budget and schedule constraints. If required, the BPR project should also consider inputs from vendors, customers, and other service providers. Thus stakeholder management plays a critical role in the success of BPR projects. Moreover, depending upon the phase of the project, such as As-Is study, Finding Solutions, To-Be process design, we need to apply variations of the standard project management methodology to suit these stages and to get optimum results.

The concept of BPR emerged from observing the practices of highly successful organisations. Thus to understand BPR, one has to learn from the world of organisational experience. It is vital to look at what others have done, their mistakes, results and overall approach to BPR. Although the critical success factors have been presented in the literature, the emphasis (whether on technical or human aspects) has varied. There is always scope to learn and change in BPR. Many challenges and pitfalls have been reported in the case studies, which were either not foreseen by theorists, or underestimated. The same holds true for the applicability of reengineering within different cultural contexts and organisational environments. Although some of these areas have been tackled by theorists, the only reliable source of information is case studies. 


\section{The case}

The case involves an engineering multinational corporation (MNC) that has manufacturing plants in North America, Europe and Asia. It manufactures more than 200 products related to the engineering and construction industries at these four manufacturing bases. As per company policy, one product is manufactured at one location only.

A BPR exercise was carried out in this engineering MNC. The structure of this engineering MNC is shown in Annexure - I to give an idea of the project scope and complications. In this structure, we have only detailed the operations of the North American arm of this organisation as the European, South American and Asian plants have the same structure. The global headquarters was in Germany and its global turnover before the start of the BPR project was about US\$ 1.2 billion.

The objective of the BPR exercise was to change the processes, so that the manufacturing of products could be moved from one continent to another within two months compared with the past record of six months. This change would save the organisation transportation costs by moving the products to more efficient manufacturing locations for that product line.

The organisation had an elaborate process for managing the products throughout their life cycle, right from the product launches to product retirement and closing support for old and retired products. This process was rigorously followed throughout all the regions as the products manufactured were engineering products requiring strict revision control of the products and tracking and tracing of the products with their revision numbers throughout the globe.

\section{Challenges}

As the organisation was global, shifting the product from one location to another had multiple challenges, including but not limited to:

\section{Bill Of Material (BOM) structure}

The North American and Asian arms of the organisation were following two levels of revision controlled Production Bill of Material (P-BOM) whereas its European arm was following multilevel revision controlled P-BOM.

\section{Working time}

As per German rules, maximum working hours per week are 35, whereas in the US, a worker has to clock minimum 40 hours a week and in Asia the minimum is 45 to 48 hours a week. These differing working hours creates an issue when setting up the standard time for completing an operation.

\section{Working culture}

In Germany alcoholic beverages such as beer are allowed on shop floor whereas in other countries, this is not allowed. Due to such liberal labour policies in Germany, the labour discipline there is different compared with the other countries. This again poses an issue with regards to how strict management can be when setting up the norms.

\section{Working environment}

In the US, generally factories follow the "unit cell" concept compared with assembly lines in Europe. These unit cells require less space and energy in material handling. So assembly norms were different in various countries. 


\section{Vendor culture}

As a result of the country's good infrastructure, it is generally accepted practice in the US to have remote vendors. In Europe and Asia vendors from shorter distances are preferred leading to some uneconomical vendor supplies.

\section{Processes}

Considering the local conditions, each of these four regions had developed 1000+ processes in manufacturing, sourcing and distribution areas. To reduce the product shifting lead time, most of these processes need be clubbed, merged or chopped to make them similarly and lean and mean.

7. Steps followed in the project

In BPR projects, we follow following steps:

$>$ Goal definition

$>$ As-Is process study

$>$ Find out candidate processes for BPR which are in line with the goal

$>$ Brainstorming for finding out alternatives to make the process lean, mean, efficient and same across all the regions

Design the new processes and pilot the implementation.

As the team composition has to be different at the different stages of the project, the project management methodology has to be changed to suit each of the above steps so that we get maximum benefits from that step.

From the above, we can understand the complexities involved in various dimensions for this BPR project. Each dimension had to be evaluated carefully and considered while planning and executing this BPR project.

\section{Methodology adopted}

Project Management Methodology as described by Project Management Book of Knowledge (PMBOK) was successfully used for the project management of this BPR project. From the stakeholder management point of view, Integration, Scope, Communications, Risk, Time, Quality and Cost were considered to be critical success factors key to the success of the BPR project and have been elaborated. 


\section{BPR methodology}

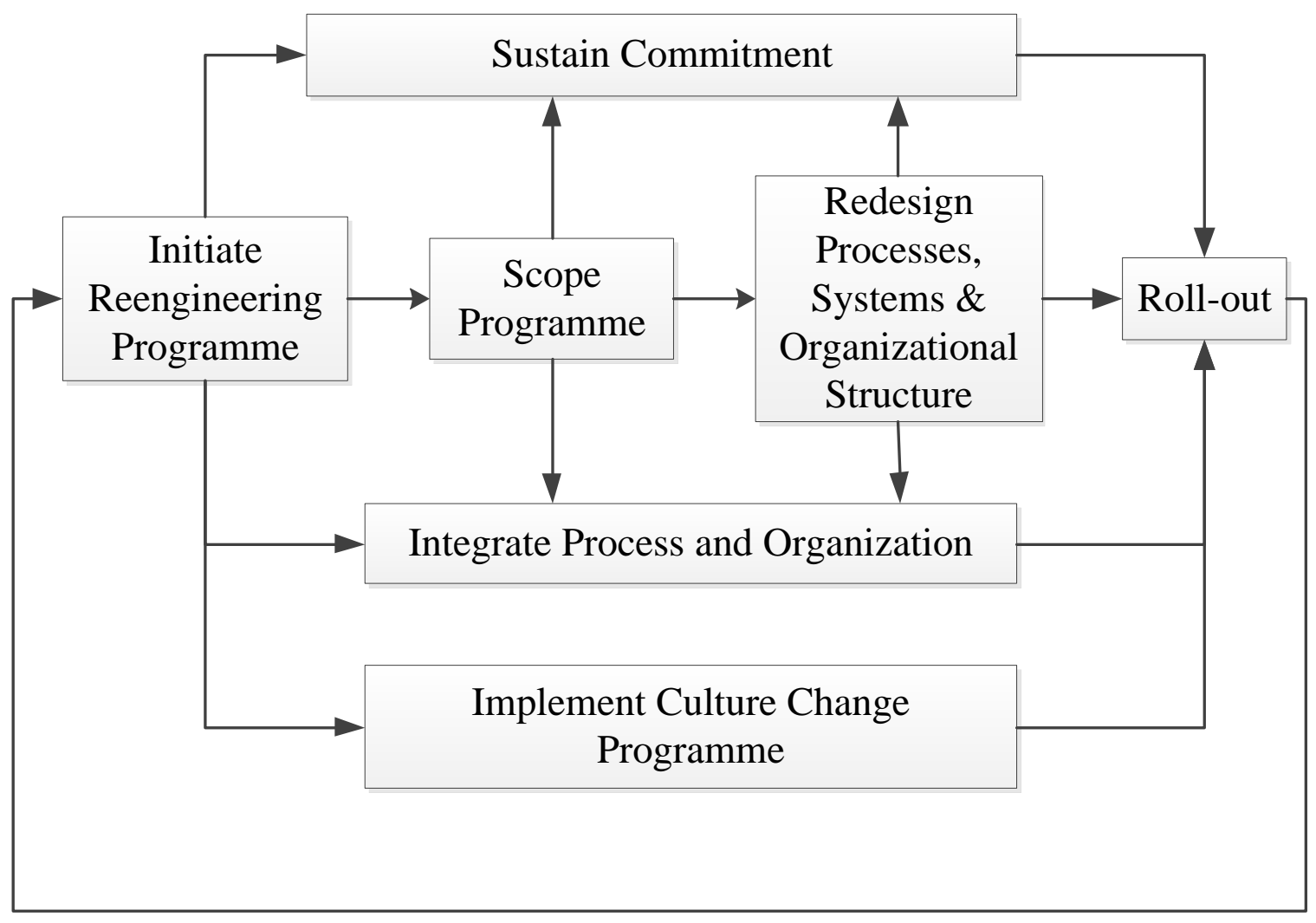

\section{Critical success factors}

a) Integration management

For this big project, an elaborate team structure for project planning, management, control and execution was defined. Two separate Project Management Offices (PMOs) were set up at two different locations, one in the US and the other in Germany. The PMO structure is given in Annexure - II.

While defining these two PMOs, it was made mandatory for them to work in tandem, so that the project did not lag behind at one location at the cost of another location.

Each Project Sponsor was directly reporting on the project progress with the highest authorities at each location. The Project Manager and the team member responsible for each area were directly interacting with department heads at their respective locations.

The business analysts provided required details of processes from their process repositories in terms of swim-lane diagrams, organisation charts, rules followed and similar details.

The BPR consultants were responsible for guiding the project team through the various stages of this project right from project assessment phase till finalising the process, so that it can be adopted at each of the location.

Any project plan amendment, integrated change control, etc. was jointly handled by both PMOs at their weekly meetings. Once approved, the changes were presented to the steering committee at their fortnightly meetings The steering committee structure is given in

Annexure - III. 


\section{b) Scope}

For a global level project spanning four continents and having more than $1000+$ processes at each level, first defining the scope and then managing it was a very big challenge. We had many sessions to define and refine the scope, so that it did not go beyond the limit and at the same time was practically achievable.

In the initial stages of the project, we thought of streamlining all the processes and making them similar including financial processes. Then we realised that due to local statues and guidelines, the financial processes could not be same in the different countries, hence accounting and booking processes were removed. Only the cost-accounting-related process for costing of the products or parts were considered in the scope of the project.

Once the scope was defined at the steering committee level, which comprised project sponsors, the main responsibility of managing the scope was with the project managers at each location. Project managers used to flag any scope deviations at their weekly meetings and, if required, at the fortnightly combined project review meeting of both teams and their project sponsors.

Any change in scope whether in was addition of scope, deletion of scope or change in scope, it was to be approved by the steering committee.

\section{c) Human resources}

The first step in human resource (HR) management is planning. So the acquisition, development and management of human resources were planned at a broad level during the project-planning phase. As the project scope became clear, the HR plan was refined from time to time to incorporate the latest details.

For this project, while planning for HR, many aspects needed to be considered as availability of desired resources at the local level (at each manufacturing location) as well as global level. Language was another barrier. One of the manufacturing locations had few employees who could understand the local language as well as English. So instead of hiring separate interpreters, a few team members acted as interpreters. Training these interpreters on technical terms and then using their services was a challenge due to shortage of time. Each manufacturing location had a different cultural and social environment. Considering this, expert consultants were needed who had experience working in a manufacturing environment in multi-ethnic projects. It was planned that each local team of consultants should have at least one local resource to guide the team for local issues.

Acquiring resources (consultants) able to meet the project requirements was a challenge at the local as well as global level. The selection of local resources gave some comfort to the local users. However, scarcity was an issue. After acquiring the resources, teams were formed and all the resources were oriented to:

$>$ Have common understanding of the project

$>$ Have some cross-cultural understanding

$>$ Decide and finalise the meeting protocols and schedules

$>$ There were eight sub-teams in each local team comprising the:

- Engineering team for making necessary changes in design and processes to suit local conditions 
- Purchase team for local vendor development and dealing with local government issues, such as taxes, etc

- Planning team for planning and scheduling of products, supply chain management, etc

- Warehousing team for inventory management and issues related to distribution

- Manufacturing team to access requirements for special tools, jigs and fixtures, special machines, etc. required so that the items could be produced locally

- Sales team for managing sales-related processes

- After-sales service team for management of sales of spare parts related to current products as well as closed-down products that were still under service

- Finance sub-team involved with costing of products.

As the resources felt that the assignment was very challenging and high profile, this created enough traction. So managing resources in such a project was not tough from a motivation point of view.

\section{d) Communications}

Each PMO had two meetings a week for managing the project at their respective locations. Apart from this, the PMOs had a weekly interaction meeting at the working committee (Project Manager) level and a fortnightly meeting at the steering committee (Project Sponsor level).

The project sponsors for each team were reported directly to the top management at each location so that all the necessary sanctions and permissions for the BPR could be received as a top priority. Both project sponsors also interacted directly with each other to resolve any issues between the two teams or for the project.

The BPR team members interacted with the department heads at each location for the area allocated to them. This ensured that they are getting up-to-date information from each location and department and the department heads were also getting information about the project progress. This ensured that there was no lag between the project team and the actual teams working in the company.

Individual team members of both teams also communicated with each other on a one-to-one basis. This ensured that the both the teams were working in tandem.

\section{e) Risk}

Since a BPR project spans many departments in a (client) company and almost all levels of management, it runs high risks. Hence, the risk management plan needs to be developed during the planning phase and updated as the project progresses.

Generally, the risks are highest in the beginning of any project and diminish as the project progresses. However, in BPR projects, the risks are high in the beginning, increase as the project progresses and then, after the best alternative is found for an existing task/process (the 'to be' solution), the risks start diminishing and become insignificant at the end of the project. The reason for the increased risks in BPR projects is due to the high visibility and high stakes of these projects. If they are unsuccessful, not only will the resources invested be wasted but the morale of the team (client as well as consulting) will also suffer and this can lead to a mass exodus and the overall working of the company will be affected. So the Project Manager has to be alert and manage stakeholder expectations until the best alternatives are found for all the tasks or activities. 
In this BPR project, the risk was planned in the beginning of the project. At every stage different sets of risks were involved. Considering this, the identification and documentation of risks was done frequently. This paid dividends, as we got very few unexpected surprises in the project.

\section{f) Time}

Since the span and scope of each BPR project varies, it is very difficult to use earlier estimates for defining the exact time schedule for a BPR project. However, the previous estimates gives some idea. In BPR projects, two processes are very unpredictable namely, pinpointing the exact issues based on the goals, and finding the solution to these issues. Generally, the BPR team under the guidance of BPR consultants identify the issues that could affect the optimisation of the goals as defined by the steering committee. However, if the team's analysis of an issue is wrong, one or more iterations may be required to find the correct issues. These additional iterations may add time and the timelines may slip.

Another step where the timelines may be at pressure is in finding the best alternative solutions to resolve the issues identified earlier. To find the best alternative, common methods used are brainstorming, Delphi method, cause-and-effect diagram, mind-mapping tools, 5 why (5Y) technique, Pareto charts, etc. To arrive at the right solution, sometimes you have to consult trade magazines, and research papers and do a competitor analysis; this also takes time.

This step requires lot of creative thinking and brainstorming: for some issues you can arrive at the best alternative solution easily; however, for others it takes time.

While estimating the time for the BPR project, we added some buffer based on the earlier estimates and at the same time, carried out the tasks in parallel so as to save time. Time management during the above 2 steps was a tricky issue as practically estimating time and efforts for these 2 steps was very difficult. Any additional time taken in these 2 steps needed to be compensated in next steps of the project such as finalizing the To-Be process with the concerned stakeholders and piloting these To-Be processes.

\section{g) Cost}

In the beginning, based on the annual targeted savings from this project, cost estimates were decided for the project. Then these estimates were broken down to different steps (As-Is study, To-Be process design, etc.) to be performed during the project. Keeping to the budgeted costs for each stage was a challenge. Considering the iterations performed in finding the best alternative process, we overshot the budget in this step. However, as the other steps were done within the defined budget, the overall project budget was under control.

\section{h) Quality}

In BPR projects, measuring the quality of the output, i.e. for each To-Be process is very tricky. We chose process efficiency as the parameter. While measuring the efficiency of the process, for the sake of uniformity we converted the process output in terms of money. While arriving at the To-Be processes, if costs were involved in terms of additional investments such as manpower, infrastructure, etc., then those investments were also considered with three years of payback period. 
In the beginning of the project, we had decided the quality parameters for the processes as follows:

1. To-Be process is $50 \%$ or more efficient than the current As-Is process - surpassing expectations. Few As-Is processes were eliminated in this exercise, hence they were put in this category.

2. To-Be process is between $25 \%$ and $50 \%$ more efficient than the current as is process - meeting expectations.

3. Any To-Be process which is less than $25 \%$ less efficient had to be reworked to bring it into the above two categories.

Another quality parameter was related to the culture. While designing a To-Be process, it was decided that local cultural aspects and laws would be considered. If any To-Be process was not in line with local cultural beliefs or laws then that process change would be omitted.

\section{Findings}

As the BPR project covered all levels in the organisational structure of the company, it needed to be planned and managed carefully. During the initial phases of this project, a core team of subject matter experts/business consultants needed to be managed. Once this team gave its recommendations and they were accepted by the client's management, the real litmus test of implementing the project at the organisation level started.

In the BPR project, the processes were set correctly as the project had a span over multiple locations; any slack process would have led to issues/failure at the local level, impacting the project severely. The critical process to design and control was communication management as it covered multiple geographical locations and cultures. Considering the cultural sensitivity, the processes were clearly defined and implemented.

Risk was planned in the beginning of the project. At every stage different sets of risks were involved. Considering this, the identification and documentation of risks documentation was done frequently. This paid the dividends, as there were very few unexpected surprises in the project.

Scope creep occurred quite frequently as there was a very fine line between "within scope" and "out of scope". However, the project team focused on the core objectives of BPR project and kept the project scope tightly controlled.

Using good analytical techniques and creativity, time and cost of project was kept well within acceptable limits as it was crucial to determine the viability of the project.

Having clear-cut quality benchmarks helped in taking prompt decisions on processes to be reengineered and finally led to the achievement of the desired BPR objectives.

Any additional points that came up during the project execution were to be taken up in the 2nd, i.e. optimisation, phase of the project.

Overall, and in spite of customer focus being seen as a key success factor, the primary uses of BPR were directly aimed at benefitting the organisation, assuming that customers and other stakeholders may also gain from improved performance result. There was a shared determination not to stop after succeeding but to go on to the next step, mainly defined by continuous improvement. A greater focus on working and learning at the expense of a preoccupation with cost and time could increase the strategic impact of BPR projects. 
The critical success factors revealed by this case study have been found to agree with most of the published BPR theory. However, these are not golden rules and it must be stressed that reengineering is about innovation and radical changes. It is anticipated that organisations will find ways to improve on the BPR process and the learning process will continue. The crux of BPR lies in change, change and change again as it pays to improve.

BPR managers need to be wary of seeking instant results. In their over-enthusiasm to achieve quick breakthroughs, they may jeopardise the success of well conceptualised BPR projects.

Hammer and Champy (1993) rightly state that BPR is more like a game of chess than roulette; you lose not because of bad luck but because you don't know the rules.

\section{References}

Magutu, P.O., Nyamwange, S.O. \& Kaptoge, G.K. (2010), Business process reengineering for competitive advantage, African Journal of Business \& Management, vol. 1, pp. 135-150.

Hammer, M. \& Champy, J. (1993), Reengineering the Corporation, HarperCollins, New York.

Reijers, H.A. \& Liman Mansar, S. (2005), Best practices in business process redesign: an overview and evaluation of successful design heuristics, The International Journal of Management Science, vol. 33 pp. 283-306.

Keeble P. (1995), A new methodology for business process re-engineering, Infor, vol. 33 no. 4, pp 234-247.

Simpson M., Kondouli, D. \& Wai P.H. (1999), From benchmarking to business process re-ngineering: a case study, Total Quality Managemnt, vol 10, no. 4\&5, pp. 717-724.

Jarrar Y. \& Aspinwall, E. (1999), Business process re-engineering: learning from organizational experience, Total Quality Management, vol. 10, no. 2, pp. 171-186.

Hale A. \& Cragg P.B. (1996), Business process re-engineering in the small firm: a case study, Infor, vol 34, no. 1, pp. $15-27$.

\section{About the authors:}

Chandrashekhar S. Joshi is a chartered mechanical engineer, software professional and project management professional, and has 23 years of experience in various industries such as automobile and auto-ancillaries, engineering, pharmaceuticals, packaging, media and entertainment and software. Apart from India, he has experience managing projects and programs in multicultural environments in the countries like the USA, Japan, etc. He has also offered business process reengineering consulting services to manufacturing companies. He founded CompuBee Technologies in 2008 and is currently working for it.

Email: $\underline{\text { c.s.joshi@ hotmail.com }}$

P.G. Dangwal is an engineering management graduate who has 16 years of experience in the manufacturing industry, and 10 years of experience in the training and education industry. Currently he a senior lecturer in the MBA Department of Shri Guru Ram Rai Institute of Technology and Science in Uttarakhand, India. He has expertise in operation research, project management, strategic management and production management. He has extensive overseas experience and has handled many turnkey projects in Godrej \& Boyce. He was a lead auditor and helped his company NHB Bearings to obtain ISO9000 and QS9000 certification. Currently he also delivers guest lectures at other engineering and management colleges in Uttarakhand. 


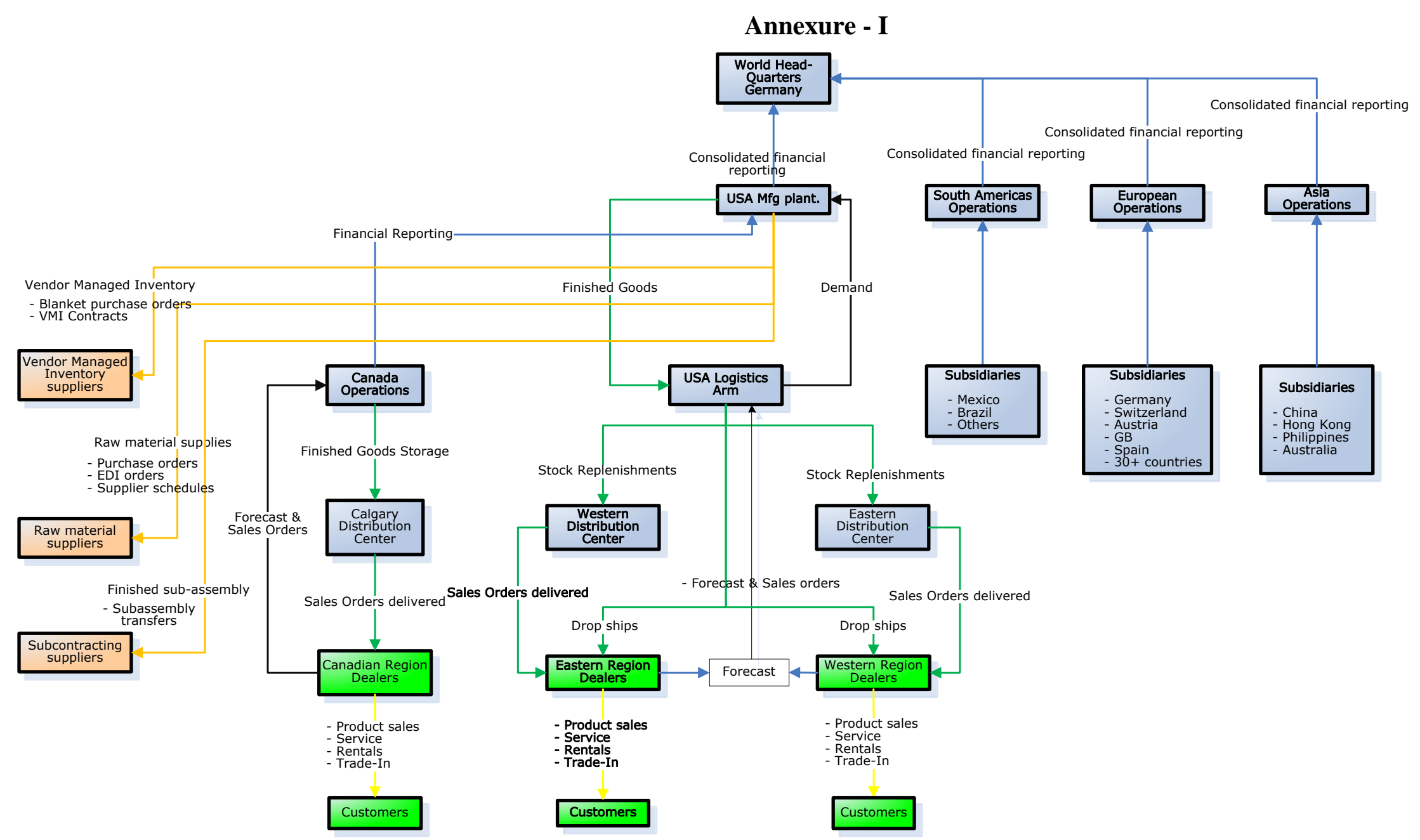

Global organisation structure of the client 


\section{Annexure - II}

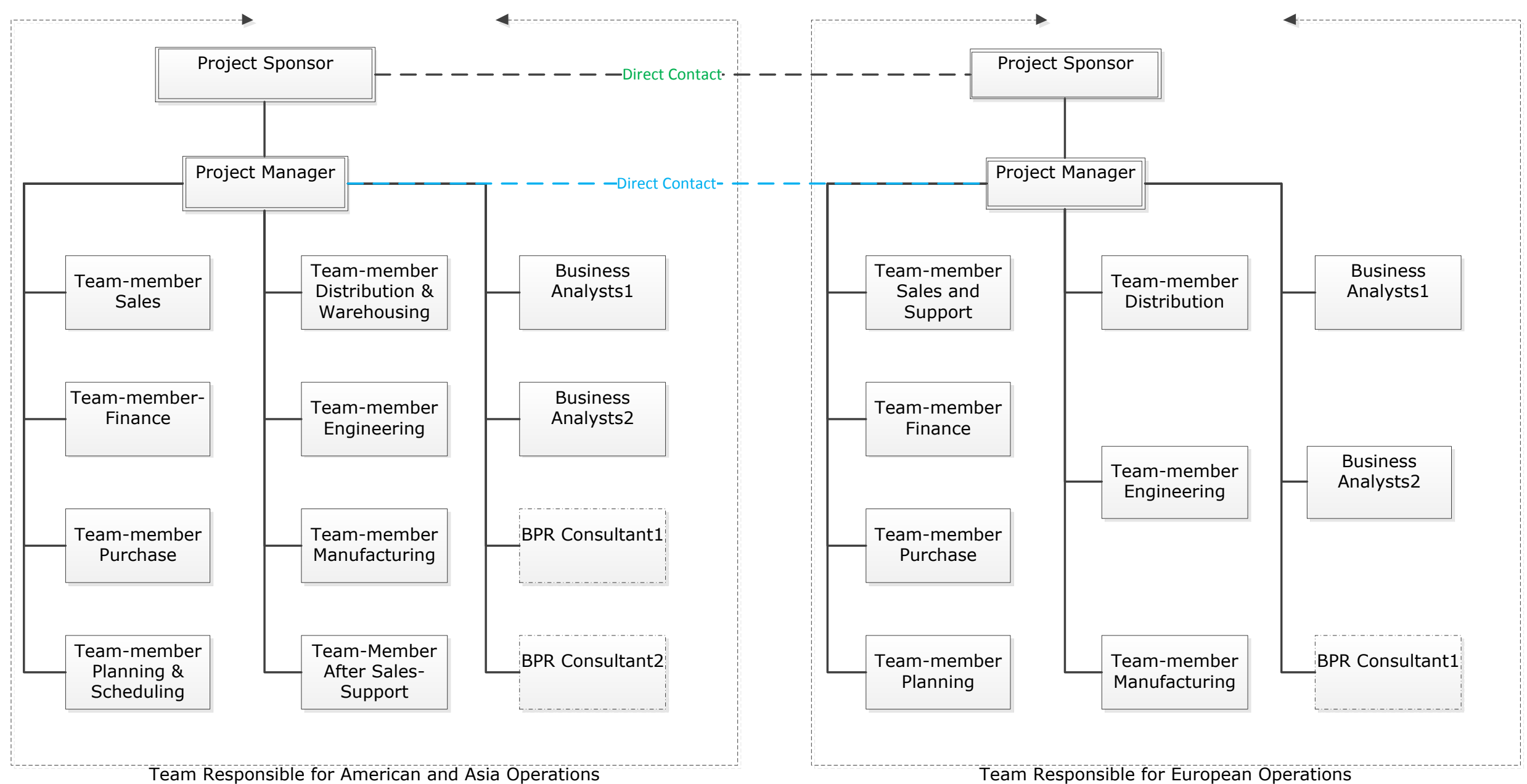

\section{PMO structure}


Annexure - III

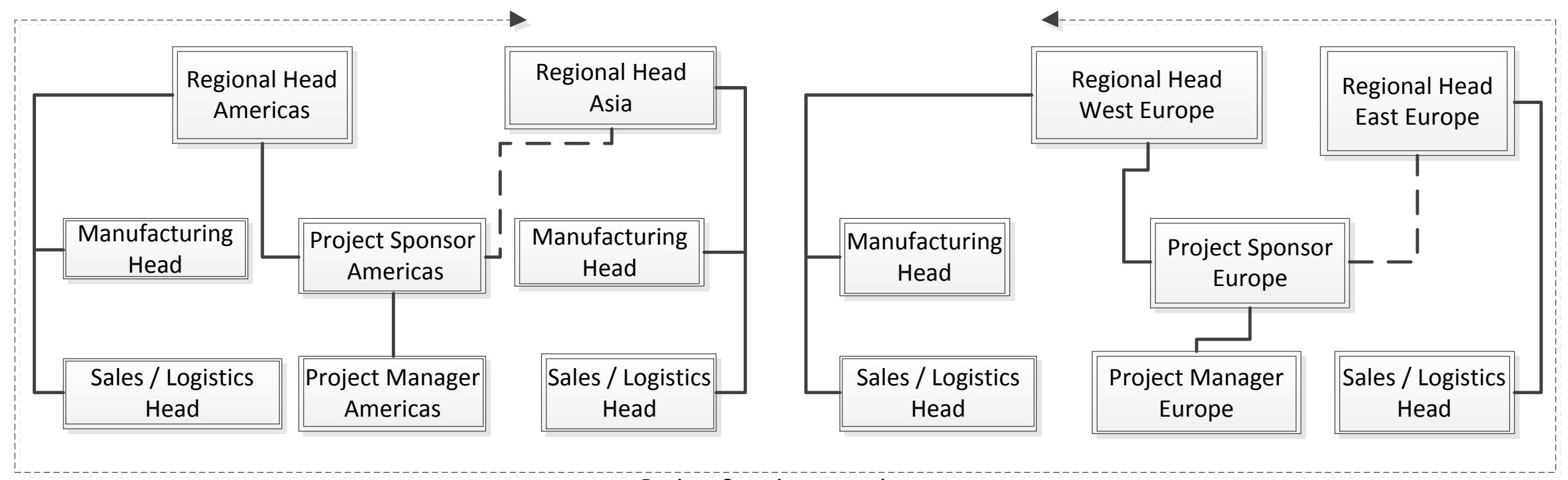

Project Steering committee

\section{Project steering committee}

